\title{
EDITORIAL
}

\section{Celebrating 10 years of Nature Reviews Endocrinology}

$\mathrm{n}$ this issue, we celebrate 10 years since the launch of Nature Reviews Endocrinology (originally titled Nature Clinical Practice Endocrinology \& Metabolism). This is a significant milestone for the journal, and I am delighted to present this special issue looking back over the past decade and forward to the next.

When the journal was launched, our aim was to 'provide timely authoritative interpretations of key research developments, translating the latest findings into clinical practice.' We set out to comprehensively cover the prevention, diagnosis and treatment of disorders of the endocrine system and related metabolic and nutritional disorders. This was a bold and challenging mission statement-endocrinology is a large and diverse field that is constantly evolving-but these aims still apply to the journal 10 years after the launch.

The past decade has witnessed a huge amount of change in the endocrinology field. Some of these changes are summarized in a collection of Decade in Review articles from five of our distinguished Advisory Board Members. Guang Ning tackles the topic of type 2 diabetes mellitus, highlighting the progress that has been made in incretin-based therapies, bariatric surgeries and inhibiting renal glucose reabsorption. Reflecting on bone research, Ian R. Reid highlights the recognition of the key role of osteocytes in bone biology as one of the most important advances in the past 10 years. Mehul T. Dattani heralds the advances in our understanding of

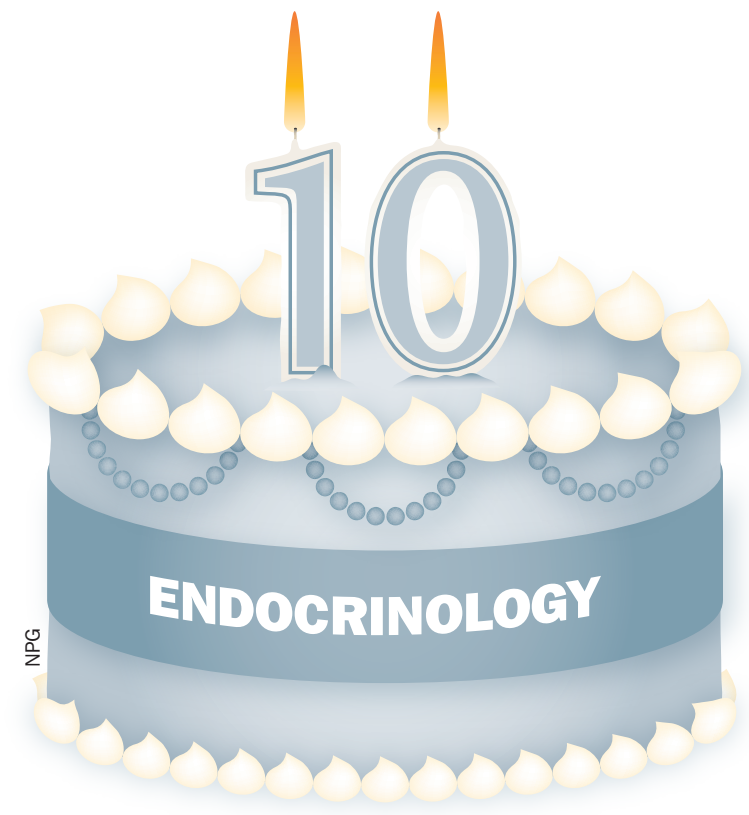

the aetiology of many paediatric disorders that have been enabled by the use of next-generation sequencing. P. Reed Larsen discusses the advances that have occurred in the diagnosis and treatment of thyroid diseases, particularly thyroid carcinomas and hyperthyroidism during pregnancy. Ursula Kaiser summarizes the key advances in reproductive endocrinology, with a focus on the neuroendocrine control of reproduction.

Our $10^{\text {th }}$ Anniversary issue also includes two Viewpoint articles. In the first Viewpoint, Kevan C. Herold, Joseph A. Majzoub, Shlomo Melmed, Merri Pendergrass and Martin Schlumberger comment on the progress and challenges in clinical endocrinology from the past 10 years. They also outline their thoughts on where money should be spent going forward and what advances might be achieved in the next 10 years. A theme that emerges from this article is how challenging it is for young researchers to establish themselves and build a career in the current climate. The second Viewpoint, written by Roger Bouillon, Daniel J. Drucker, Ele Ferrannini, Steven Grinspoon, Clifford J. Rosen and Paul Zimmet, discusses the new hormones that have been discovered in the past decade, as well as the new functions of well-known hormones and endocrine organs that have been revealed. The discussion includes how bone has been recognized as an endocrine organ, as well as the emerging understanding of the importance of gut hormones.

In the past 10 years, Nature Reviews Endocrinology has covered many of the advances discussed in our $10^{\text {th }}$ Anniversary articles. The journal has also evolved to keep up with the changing demands of the endocrinology community and with technological advances (we are now on Twitter@NatureRevEndo and Facebook). When asked to comment on the progress of the journal, founding Editor-in-Chief P. Reed Larsen said: "the remarkable increase in the impact factor for this journal to 13.281 over the past 7 years indicates that the editors and authors are meeting the needs of the endocrine community in an outstanding fashion." These kind comments are a testament to the hard work of our authors, peerreviewers and in-house staff. I would like to take this opportunity to thank all those who have contributed to the success of Nature Reviews Endocrinology-all the authors, peer-reviewers, readers, advisory board members and staff members. I look forward to seeing what the next 10 years bring to the endocrinology field!

doi:10.1038/nrendo.2015.170

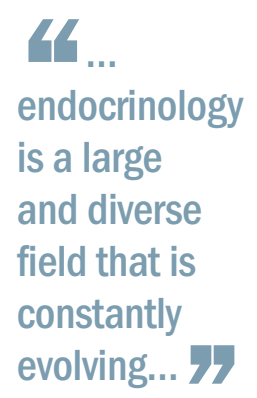

Claire Greenhill is the Chief Editor of Nature Reviews Endocrinology.

Competing interests The author declares no competing interests. 